\title{
Change Management in Public Organizations in Kosovo
}

\author{
Shefqet Zeqir Dervishaj \\ PhD Cand., The Europian University of Tirana \\ Email shefqetdervishaj@hotmail.com.
}

\begin{abstract}
One of the most difficult processes of Kosovo's postwar is the transformation of public organizations. These organizations have undergone radical changes and the process of transformation should be managed in order to be successful and to meet the needs of the market economy. Change has become a constant process for Kosovo public organizations that provide services to citizens and business organizations. Whether these changes are managed properly, then it is seen as a basis for a better performance of public organizations. Kosova after 1999 has undergone major changes in the social, economical, and political systems. Having this situation, public organizations have a great responsibility to the citizens and business organizations to provide services to adapt to the global trend of development and from which Kosova has been isolated. In this paper the focus will be on the impact of factors that affect the change process; how the process of change is developed; what are the barriers/obstacles that hinder the process of change; what are the benefits of the change; how much are managers in public organizations qualified to implement the process of change. Based on data collected from the field and from current practices, I will make their comparisons and draw conclusions about what factors influences the management changes and what are the barriers that will affect to increase efficiency and effectiveness in the organization gained from the data obtained in study. The data will be collected through questionnaires and findings obtained will help to come into a conclusion that these factors act as change management in public organizations in Kosovo.
\end{abstract}

Keywords: management of change, barriers, public organizations

\section{Introduction}

Management of change is an important issue in the current business environment which alters constantly. Changes are happening incessantly and the public organizations have to adapt to such changes.

This paper focuses on the factors that influence the change process, how does the change process develop, what are the barriers that hinder the change process, what are the benefits from the change, how prepared are the managers in public organizations to implement the change process.

The notion of management is not encompassed within one single term; Burnes (2009) provides several notions in relation to the term management. The term management refers to the process of effective and efficient realization of tasks through and with other persons, (Robbins, DeCenzo 2008). Management of change includes the well-prepared planning and sensible implementation, and above all, consultation with and engagement of persons affected by such changes. The change must be realistic, achievable and measurable. These aspects are important for the management of change. Change management is the process, means and techniques in managing people towards change of business in order to achieve the required business result and to accomplish this business change effectively within the social work infrastructure. Management of change comprises of coordination of a structured period of transition from situation A to situation B so that a sustainable change is accomplished within a certain organization (Smith, 2005).

When speaking of management of change, we encounter management everywhere: in family, at work, at school, in society, but change, also, is comprehensive and permanent which strikes in all spheres of life, be that of a human being or of an 
organization. Change management has at least three different aspects, including: adaptation to changes, control for change and impact of the change. Before starting organizational changes, one must ask oneself: what do we want to achieve with this change, why and how shall be realize that the change has been accomplished? Who was affected by such change and how will they react to it? How far can our objectives be accomplished by this change? Management of change is a process that aims keeping under control of changes as per an organized orientation of various social and economic processes that have either occurred or are in the process.

In light of the above, one can conclude that the process of change is a complicated process and, further in this paper, it will be elaborated on how public organizations in Kosovo function and how well they are prepared to manage the change.

\section{Reviewed Literature}

Change is an alteration of the environment, structure and technology or of individuals of an organization DeCenzo/Robins (2011). If it wasn't for the change, manager's work would be very easy one. Planning would be very simple, organizing would be but once organized and there would be no need for adaptation, decision-making would be very easy because the result would be foreseeable with precision.

Change is a common thread that occurs in all organizations irrespective of size, activity or seniority. The environment is affecting the organizations by changing them rapidly; thus, the organizations must change rapidly by adapting to the current requirements of the present time where managers play they key role with regards to analysis of the needs for change, preparation of the action plan and to anticipate the barriers they might encounter during the course of implementation of the change. In point of fact, managers' work would be simple should competitors of the organization not place new products in the market, should clients have no new requirements, should the governmental decisions never be modified, should there be no new technology, the requirements of the workers would always be the same. Hence, organizations do not change only because of systems, processes or new organizational structures, but also because people within the organizations also change and adapt and only then, when people within an organization have completed their personal changes, can such organization truly harvest victory.

Changes need a catalyst for them to be accomplished. Individuals that serve as catalysts and take over responsibility of managing the change process are called Change Agents, E. Sannon (2002). Every manager may be a change agent, but the change agent may not be a manager; it may be an in-house staff expert, or it may be an external consultant, the mastery of whom is precisely the implementation of change. In the events when changes in the system are really enormous, usually external consultants are engaged because they are more objective than the internal agents. However, they also display problems due to lack of knowledge of mentality, background, culture, operational procedures, etc.

Organizational change is any change that performed by managers in order to change the existing situation Llaci (2002). With vast majority of authors, all factors of change are divided into external factors and internal factors. External factors consist of legal-political factors, socio-cultural factors, technological and economic factors; whilst the internal factors consist of factors of processes and human factors.

Two metaphors are oftentimes used in relation to management of change - the metaphor of still waters and the metaphor of rushing waters. The practice and many theorists have asserted that nowadays managing resembles more to the metaphor of rushing waters because environments are both unsafe and dynamic. Until recently, the 'still waters' metaphor has dominated the thoughts of managers and researchers. This theory was best described by the three steps of change provided by Kurt Lewin (K. Lewin, Field Theory in Social Science, New York, Harper \& Row, 1951). According to Lewin, as shown in the scheme presented below, there exist three steps in the change process. First there is unfreezing, then comes change and finally comes re-freezing. There are several driving forces that wish to move the status-quo, to unfreeze it and have a new situation created which will be frozen and remain sustainable. 


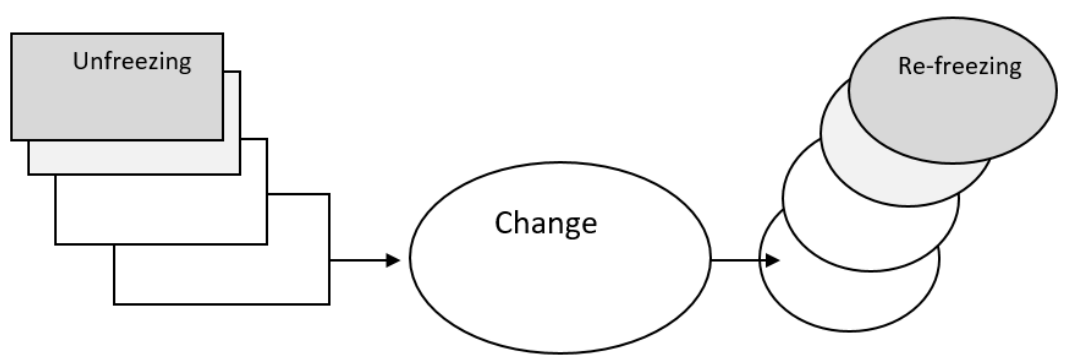

Scheme 1. Change Process, source Robina/DeCenzo, , Bazat e menaxhimit" [Fundamentals of Management], Tirana, 2011.

Unfreezing is the first phase of change which includes preparing the organization to accept changes, that changes are necessary which include separating the existing balance before a new operating manner is created. This is the most difficult part because first the staff has to be prepared as to why change has to come about, what are the benefits from such change.

Change is the second phase; it is a phase when individuals begin solving their insecurity and they begin seeking ways to do things. The transition from unfreezing to change does not happen overnight; therefore, people need some time to accept the new direction and to actively participate in the change. During this period of time people have to understand that the changes bring goods.

Re-freezing takes place once people have accepted the new ways of working, the organization is ready to freeze. The first signs of re-freezing are a stable diagram of the organization.

The metaphor of rushing waters takes into consideration the fact that where the organizations perform, the environments are dynamic and insecure. Managers must bear in mind that anticipation of still waters does not exist at present time which is full of vigour and changes. Many a managers fail to come out of rushing waters and constantly confront with changes. In Kosovo every organization confront constantly with changes and almost all managers, of whatever rank they may be, are forced to be cautious because every new change requires effective management and surmounting every change represents a challenge on its own.

Besides facing continuous changes in legislation, public organizations have also undergone operational changes, starting from the new access of data processing, a new system of records, most of organizations offering online services, changes that managers dealt with and consequently the entire staff. All these changes have aroused reactions of the staff which had to be managed with the utmost attentiveness. All these have influenced an increase in the volume of tasks and emergence of the great need for training of staff in relation to the new changes. There was undoubtedly a need for constant changes with the first and foremost purpose to enable citizens and businesses an easier and more efficient access for their completion but at the same time their request for realization of services by the public organizations.

\section{1 Principles of Change Management}

According to Mercurio (2006), change can be managed in the best manner by: frequent and honest communication, explaining the purpose of the change, by providing a detailed implementation plan and by monitoring the plan and separating facts.

While planning change, one must consider five basic principles, and they are:

Principle 1 - Obtaining support so that at any given time it involves and obtains the support of the personnel within the system, environment, processes, culture, personal and organizational relations. 
Principle 2 - Understanding current situation. A manager must understand the organization at a certain moment by collecting and analysing data and to have an accurate description of the organization.

Principle 3 - Anticipating future situation. One must understand where it is heading, when, why and what measures must be undertaken to accomplish the desired situation.

Principle 4 - Plan development. The plan must be developed in phases that are appropriate, achievable and measurable towards accomplishing of the future situation.

Principle 5 - Communication. This is an unavoidable and most important principle which is included in every phase of management which enables facilitation of participation of personnel who must be informed as promptly, openly and comprehensively as possible.

Therefore, most of these factors are identifiable but how do these factors influence change management, we shall see in the continuance of the paper.

\section{2 Why Can Change Fail}

There are various reasons why change can fail. Articulating and designing initiatives of change is relatively easy. However, effective implementation and execution of initiative in order to gain its perceived result, is something else. To avoid failure and to increase probability, one must as much as possible strive to avoid errors that usually others make. There are several reasons why change can fail.

Failing to Focus on Essential Issues - If a preparation of initiative for a certain change has lasted too long and the executioners have grown tired of this and they lose attention due to the long time and they wish to announce the change as soon as possible only so that the issue moves forward, they can make essential errors. They forget that people they depend on for the implementation of change have not been part of preparations and talks. Good managers, who wish to circumvent these situations, value the emotional impact of the initiative for change. They focus on time for people who process these changes.

Failing to Remind People on the Necessity of the Change. Following a certain time of preparation for change, the implementation team is ready to announce the change. The problem is in it that communication that the executors have with their employees is that they forget that people who work for them do not think like them and they do not have the same information. Great leaders remind their people why change is necessary.

Executors Often Forget that Everything is a System. When we say system, we are dealing with connected parts whereby any change in one part affects the other part of the system. Therefore, if a change takes place one must take into account side effects that might occur.

Failing to Create Executable Plans. Nonexistence of executable plans may be one of the causes for nonrealization of change. Hence, a strategy must be developed which is an executive function and tactics must be developed which is an operational function. Answers must be provided to the following questions: who, what, where, whne and how. Finally, it must also contain the motivating component and a connection with rewards.

Failing to Anticipate Obstacles, Delays and Resistance. In the course of realization of a plan, there are inevitably various problems, obstacles, which hamper its implementation. Therefore, it must be taken into consideration what might go wrong and it must be prepared for and be cautious with regards to the obstacles that will emerge by creating a second or so-called plan-B. Every effective manager must have a plan-B in case of emergence of an obstacle, he will activate it, and this is done when we anticipate possible obstacles that migh appear during the implementation of the change.

Improper Coordination of Necessary Resources. One of the reasons why the initiative for a certain change fails is that the executors do not restructure the required resources. If the attempt for a change will be successful, then human resources must be reorganized so that the success becomes possible. This means that people, processes, finances, training and operations must be restructured so that the proper people are in the proper positions with appropriate resources and 
capacity to make the attempt for change optimally successful. If one of these points, such as: reorganization, probability of initiation and completion of successful attempts in realizing of change, does not go as planned, then the chances for success will diminish. Change is a usual thread which occurs in all organizations, irrespective of size, activity or seniority. The environment is changing rapidly, thus affecting organizations and, therefore, organizations must also change rapidly. "Change is an alteration of environment, structure, technology or individuals of the organization". Victor \& Franckeiss (2002); Cao et al (2003); Clegg \& Walsh (2004); Stanleigh (2008). The organization is constantly subjected to changes which have to be managed and if there would not be changes, the work of managers would be very easy. Actually, the work of managers would be simple if the competitors of the organization would not place new products in the market, if clients would not have new requests, if governmental decisions would never be modified, if there would not be new technologies, the requirements of employees would always be the same. Therefore, organizations do not change only because of systems, processes or new organizational structures but also because people within the organization also change and adapt and only when people within the organization have accomplished their personal changes can an organization really harvest victory. Changes require a catalyst for them to be realized. Individuals that serve as catalysts and take over responsibility of managing the change process are called change agents. Every manager might be a change agent, but a change agent might not be a manager, it might be an internal staffing expert or an external consultant, whose mastery is precisely implementation of change. In the events when changes are immense in system, usually external consultants are engaged because they are more objective than internal agents. However, problems also appear with these agents due to lack of knowledge of mentality, background, culture, operational procedures, etc.

It must be pointed out that in most public organizations, trainings were held with managing staff, and I will mention here a source from the TAK, where the process of change management has been described splendidly and I am using this source in this case. Amongst others, the phases of change have been described here as following.

\section{3 Phases of Change}

Having a change occur within an organization, the challenge does not consist only in regulating systems, processes and structure but also people are assisted and supported through individual changes which sometimes can even be traumatic.

The model of the change curve describes four phases which most of people go through until they are adapted with the change

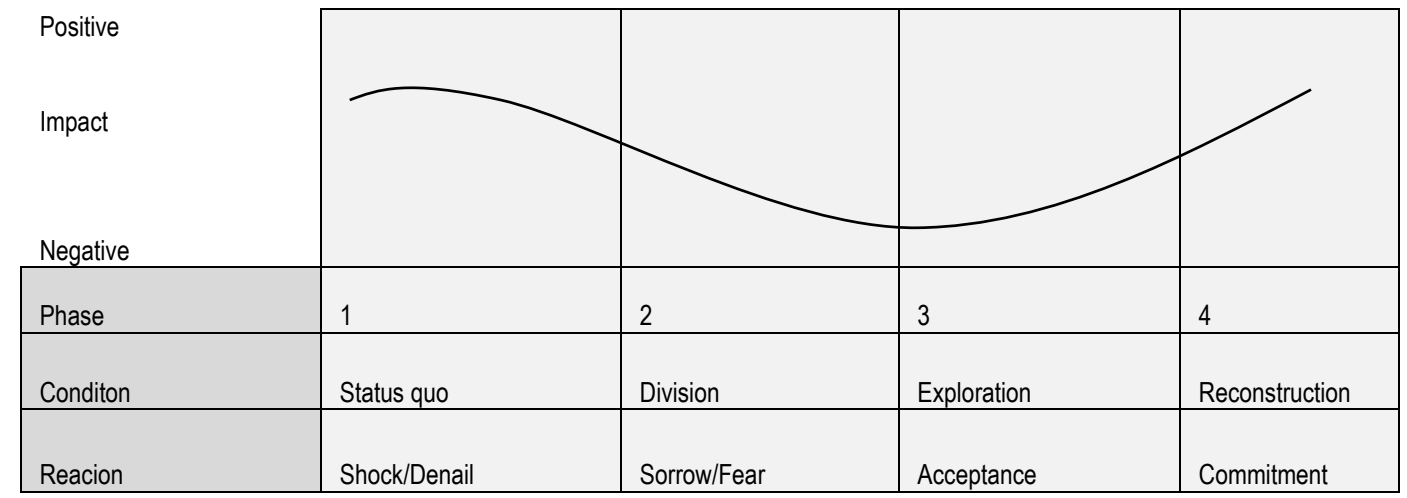

Scheme 2. Model of the change curve, source from "Tax Administration of Kosovo" 2011.

First phase deals with the notifying of people with the change, people's initial reaction may be shocking because they react towards the challenge through denial. Moreover, even if change is well planned and it is comprehended what is about to happen, the reality of change strikes the employees and it takes them some time to adapt. What's important in this phase is communication. Frequent communication must be facilitated but the employees must not be confused because they have little possibility to receive timely information and one must dedicate time to answer their questions. 
Second phase is when people begin to react to changes and the employees begin to feel concerned, agitated or frightened. Their resistance may be expressed in the form of a need to express their concern and to release their anger. Experience showed that this is a phase in "dangerous zone" and it must be managed with utmost attentiveness for if it is not managed well, then it can develop into crisis and chaos. It is important that even in this phase clear communication and support is provided and actions are undertaken aiming to minimize and mitigate the problems that people will be facing.

Third phase is a turning point for the employees of the organization. In this phase, the organization begins to emerge from the dangerous zone and is on the right path for success in changes. When acceptance of change is increased by people, they will have to test and explore what changes consist of. The team manager is the person implementing these changes by ensuring that people are well trained and are prepared for the consequences brought by the change and it is a phase that takes a lot of time to get used to and accept change.

Fourth phase is the phase when realization of what was expected by change is completed and employees are embodied with and embrace improvements in order to carry out their tasks and meet the anticipated objectives. Normally, changes are made for enhancing the work results and the organization starts being more productive and efficient, and the effects of change are made visible by DeCenzo/Robins (2011).

At KTA, besides changes in legislation that the staff faced with, there were continual operational changes, starting from the approach to data processing, new system of records, electronic reporting, cash registers, stimulation of voluntary declaration by frequent contacts with taxpayers and informing the same with their obligations, etc. All these changes have provoked reactions of the staff which had to be managed with the utmost caution. All these have prompted an increase in the volume of works and an immense need for training of the staff with regard to new changes. There was undoubtedly a need for constant changes, primarily with the intention to facilitate the taxpayers an easy and efficient access to voluntarily complete their tax obligations which is the motto of KTA.

Based on the conducted analysis I have ascertained that since its beginning after the war of 1999, when it was under UNMIK umbrella, and to the present days, there have been constant changes which, though trailed by problems, they inevitably occurred and have definitely had positive impacts in the modernization and development of public organization in Kosovo. The key agents of such changes were the managing staff, starting from the lowest level all the way to the toplevel management, but also without neglecting the merits of all the employees in public organizations. The necessity for changes in public organizations was made for practical reasons, in order to fulfil their mission and vision for what they have been established in the first place, i. e. to become modern organizations that provide professional services both to citizens and business organizations and thus created a positive image for Kosovo state.

\section{PURPOSE AND OBJECTIVES OF THE STUDY}

This paper aims to answer some research questions in relation to management of change in public organizations in Kosovo. The main aim is to indicate factors that affect the success of change in public organizations. In addition, the purpose of this research is to identify changes that have occurred within public organizations, and secondly, to have a real overview of change management in public organizations. Empirical data serve us to have a clear view of the structure of general changes that have taken place. The objectives of this research are as following:

How much are changes happening in public organizations and how does it affect their performance

What is the commitment of managers in accomplishing changes, how effectively does the information flow and how well are staff trained in relation to the change process

Do public organizations have a clear vision with regards to the purpose of changes

How well are employees prepared pertaining to changes

How does information flow from the top-level management to the other employees and vice-versa; i. e. how does communication function in general. 


\section{METHODOLOGY}

Quantitative method was used in this research in realizing the research, more specifically, techniques and questionnaires were utilized in data-collection process. Participants were employees of public organizations in Kosovo. However, according to Ford \& Greer (2005), regardless of the fact that researchers usually suggest qualitative methods in understanding the change process, completion of empirical researches can assist them in pursuing this issue. On the other hand, in order to answer the three research questions indicated below, it is required to carry out a testing of connection between variables (communication, effective management, employees' training). Testing of these connections is made possible by use of quantitative methods. The total number of participants in the research was 32 . Prior to applying questionnaires, participants agreed to serve as respondents in this research; hence, their participation was on voluntary basis. Before preparing questionnaires, some qualitative interviews were conducted, problems were identified and research questions were raised.

\section{1 Research Questions}

Based on the qualitative interviews and based on fundamental principles in relation to changes, the following research questions emerged:

How much can effective communication affect the change process in public organizations?

Do public organizations have effective management pertaining to change?

What is the impact of training programs in the process of change in public organizations?

All research questions are based on the fundamental principles of management.

\section{2 Hypothesis}

The questions raised above with regards to the management of change generated the research hypothesis.

H1. Effective communication facilitates change process in public organizations.

Based on changes performed in public organizations, starting from changes such as strategy, leadership, organizational culture, public organizational structure and management practices, communication represents a problem as a very significant factor.

$\mathrm{H} 2$. Management in public organizations is committed to implementing changes.

Qualitative interviews resulted with conclusions that the leadership within public organizations display a high level of commitment; there are leaders who possess good interpersonal skills and who are committed and influence the implementation of change; nevertheless, it is expected that the qualitative interviews will prove whether they are committed to implementation of changes.

H3. Training programs affect positively the change process in public organizations.

Training programs are good prerequisites for the public organizations to successfully manage the change process; but, how much have these trainings impacted the managing of change will be revealed by questionnaires and we shall conduct a test of the hypothesis.

\section{FINDINGS}

Henceforth we do have the empirical data with regards to changes that have occurred in public organizations which we have extracted from the research data. We have in total interviewed 32 respondents in various public organizations and belonging to various managerial levels. 
The questionnaire consists of 11 questions which relate to the subject of the research and in the part of research we have opted Linker level (1-4). Below we shall present several tables containing cumulative empirical data from the research which have been calculated by SPSS.

Testing hypothesis 1. Effective communication facilitates change process in public organizations.

Table 1: Correlation between effective communication and the process of realization of changes

Correlations

Effective communication Process of realization of changes

\begin{tabular}{llll}
\hline \multirow{2}{*}{ Effective communication } & Pearson Correlation & 1 & $.815^{* *}$ \\
& Sig. (2-tailed) & & .000 \\
& $\mathrm{~N}$ & 32 & 32 \\
& Pearson Correlation & $.815^{* *}$ & 1 \\
Process of realization of changes & Sig. (2-tailed) & .000 & 32 \\
& $\mathrm{~N}$ & 32 & 32 \\
\hline
\end{tabular}

${ }^{* \star}$. Correlation is significant at the 0.01 level (2-tailed).

In order to test the first hypothesis of this research: "Effective communication facilitates change process in public organizations", the correlation was analysed and we have this statistical product $\left[r=.815^{* *}\right.$ and $\left.p<.000\right]$. This hypothesis was tested with the total of question 5 , effective communication, and with the total of question 11 , realization of changes process. This hypothesis was entirely substantiated. This shows that communication is a very important factor in the realization of process of changes in public organizations.

H2. Management in public organizations is committed to implementing changes.

Table2: Correlation between management of public organizations and implementation of changes

Correlations

\begin{tabular}{llll}
\hline & & $\begin{array}{l}\text { Management in public } \\
\text { organizations }\end{array}$ & Implementation of changes \\
\hline \multirow{3}{*}{ Management in public organizations } & Pearson Correlation & 1 & $.806^{* *}$ \\
& Sig. (2-tailed) & & .000 \\
& $\mathrm{~N}$ & 32 & 32 \\
Implementation of changes & Pearson Correlation & $.806^{* *}$ & 1 \\
& Sig. (2-tailed) & .000 & 32 \\
\hline
\end{tabular}

**. Correlation is significant at the 0.01 level (2-tailed).

The second hypothesis of this research: "Management in public organizations is committed to implementing changes", was tested by collecting the total of points from questions no. 2 and 5 , and this total was denominated "Management in public organizations", and with the total of questions no. 3 and 4, which was denominated "Implementation of changes".

Subsequently, the analysis of the correlation between these two variables was performed and we came up with this statistical result $\left[r=.806^{* *}\right.$ and $\left.p<.000\right]$ which is significant. The management is committed as it regards to implementation of the process of changes. 
H3. Training programs affect positively the change process in public organizations.

Table 3: Correlation between training programs that affect positively changes in public organizations.

Correlations

\begin{tabular}{llll}
\hline & & $\begin{array}{l}\text { Training programs that affect } \\
\text { positively }\end{array}$ & $\begin{array}{l}\text { Changes in public } \\
\text { organizations }\end{array}$ \\
\hline $\begin{array}{l}\text { Training programs that affect } \\
\text { positively }\end{array}$ & Pearson Correlation & 1 & $.925^{* *}$ \\
& Sig. (2-tailed) & & .000 \\
& $\mathrm{~N}$ & 32 & 32 \\
Changes in public organizations & Pearson Correlation & $.925^{\text {** }}$ & 1 \\
& Sig. (2-tailed) & .000 & 32 \\
\hline
\end{tabular}

**. Correlation is significant at the 0.01 level (2-tailed).

Third hypothesis of this study: "Training programs affect positively the change process in public organizations", was tested by collecting the total of question no. 8 and by denominating is "Training programs that affect positively" and with the total of question no. 9 which was denominated "Changes in public organizations". Accordingly, an analysis was performed in relation to correlation between these two variables and we came up with the following significant statistical result [r=. $925^{* *}$ and $p<.000]$.

Based on all mentioned above, we can render a conclusion that communication within the organization, managers' commitment and training of the employees, are of great importance in managing the change process.

\section{Conclusions}

Public organizations in Kosovo have constantly been subjected to changes, both in the legislative and organizational aspect, since after the war to the present day. Undoubtedly they have confronted predicaments during the process of changes considering specifics of public organizations which are not so flexible and all the processes that take place are rather slow and they take time to submit to the processes of change.

All changes that have occurred, exempting a few which did not prove successful, in general every change has yielded in increase in the performance and a quality in completion of tasks, as well as providing services for citizens and business organizations.

Looking at it from a general viewpoint, public organizations dedicated significant importance to training of their managing staff as well as actors that are affected by the change process. We can point out here the Kosovo Tax Administration which is the most positive example in this aspect by organizing trainings for its staff, and on the other hand, organizing workshops with taxpayers in relation to changes in legislation caused by these changes, and which have been quite frequent. Resisting change is neither good nor bad per-se - it may be grounded or not, but it is always an important signal requiring further investigation by the management. Resistance is oftentimes misinterpreted as if people do not wish to change. Actually, people want to grow and develop in organization. Empirical data on the changes that have been conducted indicate that a factor in change is the good leadership which affect vigorously the implementation of change and there are other significant factors which influence the change.

Calculation of empirical data indicates that all hypotheses raised with regard to the change process are significant. Communication is the key factor in implementation of process of changes. It must be communicated frequently and honestly. Commitment and advancement of managing staff and of employees must be increased by way of trainings and motivation. 


\section{Recommendations}

Change management is a challenge that managers and the entire staff confront with. Taking into account the significance management of changes has for public organizations, as well as for any other organization, and based on the mentioned above in this study, we can wield some recommendations.

Planning of changes in public organizations must be carried out with an excessive caution throughout all the phases, starting from familiarising with problems which have to be the starting point for change, and knowing the possibilities, analysing the situation and presenting ideas, familiarising with obstacles that may appear, determining the best choice, implementation of planned and controlled change and evaluation of results.

It has been proven in this study that during the process of change communication is of special significance. Therefore, effective communication must be employed in all the phases.

Familiarising with external and internal factors must be performed consistently.

Trainings are essential for the managing staff as well as for employees in order to have them prepared for the change process.

I would recommend to have a specific agency established which is specialized on changes and which would prepare managers for changes. This agency would serve as a change agent which would exclusively deal with the change process. I support this due to the reason that time is being spent in training, first of managing staff and then vast majority of employees who are affected by change. This would relieve the management staff to carry out their managing duties and other employees would be closer to completing operational tasks.

Another recommendation deals with motivation which does not occupy a significant place in public organizations. Forms must be found to motivate successful managers in career advancement or some other material form, and this motivation in public organizations leaves a lot to be desired.

\section{References}

Burnes B. , (2009), Managing Change: A Strategic Approach to Organisational Dynamics, FT Prentice Hall, fifth edition.

Cao G. , Clarke S. , Lehaney B. , (2003), 'Diversity Management in Organizational Change: Towards a Systemic Framework', Systems Research and Behavioral Science, 20, 231-242.

Ford M. W. , Greer B. M. , (2005), 'Implementing Planned Change: An Empirical Comparison of Theoretical Perspectives', Mid-American Journal of Business, vol 20, no 2, 59-69.

Lewin K. , (1951), Field Theory in Social Science, New York, Harper\&Row, 1951

Llaci Sh. , (2010), Menaxhimi, [Management]Tirana

Mercurio N. , (2006), Managing Change Successfully, The Canadian Manger, 31/2 ABI/INFORM Global

Robbins Sh. , (2008), Leading and Managing Change in a Dynamic Environment

Robins S. , DeCenzo D. , (2011) "Fundamental of Management" Tirana, 2011

Smith I. , (2005), 'Continuing Professional Development and Workplace Learning 13, Resistance to Change - Recognition and Response', Library Management, volume 26, no 8/9, 519-522

Sannon E. , (2002), "Agjenti i ndryshimit", [Change Agent], Time, 4 March 2002, f. 17 
Victor \& Franckeiss, (2002), , "The Five Dimensions of Change: An Integrated Approach to Strategic Organizational Change Management', Strategic Change, 11, 35-42.

Van de Ven A. H. Poole M. S. , (1995), 'Explaining Development and Change in Organizations', Academy of Management Review, vol 20, no 3, 510-540.

Tax Administration of Kosovo, "Management to Results - Management Changes" Digest, 2011 